\title{
Spine surgery under awake spinal anesthesia: an Egyptian experience during the COVID-19 pandemic
}

\author{
Mohamed Fawzy M. Khattab, MD, ${ }^{1}$ David A. W. Sykes, AB, ${ }^{2}$ Muhammad M. Abd-El-Barr, MD, PhD, ${ }^{2}$ \\ Romaric Waguia, RN, Msc, ${ }^{2}$ Amr Montaser, MD, ${ }^{3}$ Sherief El Ghamry, MD, ${ }^{4}$ and \\ Youssry Elhawary, MD4
}

${ }^{1}$ Orthopaedic Department, Ain Shams University, Cairo; ${ }^{3}$ Aneaesthesia Department, As-Salam International Hospital, Cairo; ${ }^{4}$ Orthopaedic Department, Cairo University, Cairo, Egypt; and ${ }^{2}$ Department of Neurosurgery, Duke University Medical Center, Durham, North Carolina

\begin{abstract}
OBJECTIVE Despite tremendous advancements in biomedical science and surgical technique, spine surgeries are still associated with considerable rates of morbidity and mortality, particularly in the elderly. Multiple novel techniques have been employed in recent years to adequately treat spinal diseases while mitigating the perioperative morbidity associated with traditional spinal surgery. Some of these techniques include minimally invasive methods and novel anesthetic and analgesic methods. In recent years, awake spine surgery with spinal anesthesia has gained attention as an alternative to general anesthesia (GA). In this study, the authors retrospectively reviewed a single-institution Egyptian experience with awake spine surgery using spinal anesthesia during the COVID-19 pandemic.
\end{abstract}

METHODS Overall, 149 patients who were admitted to As-Salam International Hospital in Cairo for lumbar and lower thoracic spine surgeries, between 2019 and 2020, were retrospectively reviewed. Patient demographics and comorbidities were collected and analyzed. Visual analog scale (VAS) and Oswestry Disability Index (ODI) scores were assessed at different time intervals including preoperatively, immediately after surgery, and 1 year postoperatively. Patient satisfaction was queried through a questionnaire assessing patient preference for traditional anesthesia or spinal anesthesia.

RESULTS Of the 149 patients who successfully received spine surgery with spinal anesthesia, there were 49 males and 100 females. The cohort age ranged from 22 to 85 years with a mean of 47.5 years. The operative time ranged from 45 to 300 minutes with a mean estimated blood loss (EBL) of $385 \pm 156 \mathrm{~mL}$. No major cardiopulmonary or intraoperative complications occurred, and patients were able to eat immediately after surgery. Patients were able to ambulate without an assistive device 6 to 8 hours after surgery. Decompression and fusion patients were discharged on postoperative days 2 and 3, respectively. VAS and ODI scores demonstrated excellent pain relief, which was maintained at the 1-year postoperative follow-up. No 30- or 90-day readmissions were recorded. Of 149 patients, 124 were satisfied with spinal anesthesia and would recommend spinal anesthesia to other patients. The remaining patients were not satisfied with spinal anesthesia but reported being pleased with their postoperative clinical and functional outcomes. One patient was converted to GA due to the duration of the procedure.

CONCLUSIONS Patients who received spinal anesthesia for awake spine surgery experienced short stays in the hospital, no readmissions, patient satisfaction, and well-controlled pain. The results of this study have validated the growing body of literature that demonstrates that awake spine surgery with spinal anesthesia is safe and associated with superior outcomes compared with traditional GA. Additionally, the ability to address chronic debilitating conditions, such as spinal conditions, with minimal use of valuable resources, such as ventilators, proved useful during the COVID-19 pandemic and could be a model should other stressors on healthcare systems arise, especially in developing areas of the world. https://thejns.org/doi/abs/10.3171/2021.9.FOCUS21456

KEYWORDS awake surgery; minimally invasive; case series; Egypt; COVID-19; spine surgery; spinal anesthesia

$\mathrm{D}$ ESPITE tremendous advancements in biomedical science and surgical technique, spine surgeries are still associated with considerable rates of morbidity and mortality, particularly in the elderly. Trials are currently underway that seek to understand significant risk factors and reduce adverse effects associated with spine surgery. ${ }^{1}$ When seeking to reduce sources of morbidity and mortality, it is critical to ensure safe, efficacious administration of anesthesia. Currently, the most prevalent type of anesthesia used in spine surgery is general anesthesia

ABBREVIATIONS EBL = estimated blood loss; GA = general anesthesia; ODI = Oswestry Disability Index; PCR = polymerase chain reaction; VAS = visual analog scale. SUBMITTED July 29, 2021. ACCEPTED September 29, 2021.

INCLUDE WHEN CITING DOI: 10.3171/2021.9.FOCUS21456. 
TABLE 1. Patient demographics and characteristics

\begin{tabular}{cc}
\hline & Value \\
\hline Mean age \pm SD, yrs (range) & $47.5 \pm 19.3(22-85)$ \\
\hline Sex, $\mathrm{n}(\%)$ & $49(32.8)$ \\
\hline $\mathrm{M}$ & $100(67.1)$ \\
\hline $\mathrm{F}$ & $31.3 \pm 6.3(20-43)$ \\
\hline Mean BMI $\pm \mathrm{SD}$ (range) & \\
\hline Comorbidities, $\mathrm{n}(\%)$ & $45(30.2)$ \\
\hline Smoking history & $20(13.4)$ \\
\hline Hepatitis C virus positive & $26(17.4)$ \\
\hline Hypertension & $28(18.8)$ \\
\hline Diabetes & $1(0.7)$ \\
\hline Polycystic kidney disease & $1(0.7)$ \\
\hline G6PD deficiency & $6(4.0)$ \\
\hline Bronchial asthma & $2(1.3)$ \\
\hline Monocular vision &
\end{tabular}

G6PD = glucose-6-phosphate dehydrogenase .

(GA). GA is not without its drawbacks, however. These include complications that affect cognition and cardiopulmonary systems as well as postoperative nausea and vomiting. ${ }^{2,3}$ Thus, recently there has been an increased interest in regional or spinal anesthesia in spine surgery. These techniques may allow faster recovery for patients and are not associated with the same possible complications as GA.

There are considerations that must be taken when contemplating spinal anesthesia. These include issues with redosing, the ability to use neuromonitoring, and cardiopulmonary concerns when patients are positioned prone. There are also recently emergent advantages to spinal anesthesia. The COVID-19 pandemic has affected the medical landscape in immeasurable ways. One major change has been the need to prioritize ventilators, especially in countries without immense healthcare resources and expenditures. However, despite the pandemic, chronic illnesses such as back pain did not decrease. ${ }^{4,5}$ Thus, there is a need to take care of these patients without overutilizing important resources such as ventilators or putting patients at increased risk of contracting COVID-19. Spinal anesthesia, with its reduced resource footprint, may provide this ability.

There are few large-volume studies on the use of spinal anesthesia for spine surgery. In this study, we retrospectively reviewed a single-institution Egyptian experience with awake spine surgery using spinal anesthesia during the COVID-19 pandemic.

\section{Methods}

We present a case series of 149 patients admitted to As-Salam International Hospital in Cairo, Egypt, for lumbar and lower thoracic spine surgeries between 2019 and 2020. Informed consent was obtained before every procedure and all operations were performed by the same surgical team. Patient demographics and comorbidities are
TABLE 2. Type of operation

\begin{tabular}{|c|c|c|c|}
\hline Op Type & $\begin{array}{l}\text { No. of Pts } \\
(n=149)\end{array}$ & $\begin{array}{l}\text { Operated Level } \\
\text { (no. of pts) }\end{array}$ & $\begin{array}{c}\text { Total No. of } \\
\text { Operated Levels }\end{array}$ \\
\hline $\begin{array}{l}\text { Revision of posterior } \\
\text { spinal fusion }\end{array}$ & 11 & $\begin{array}{r}\text { L2-5 (1) } \\
\text { L3-5 (4) } \\
\text { L4-S1 (6) }\end{array}$ & 23 \\
\hline $\begin{array}{l}\text { Removal of instru- } \\
\text { mentation }\end{array}$ & 5 & $\begin{array}{r}\mathrm{L} 1-2(2) \\
\mathrm{L} 4-5(2) \\
\mathrm{L} 5-\mathrm{S} 1(1)\end{array}$ & 5 \\
\hline TLIF w/o cage & 15 & $\begin{array}{r}\text { L4-5 (8) } \\
\text { L5-S1 (6) } \\
\text { L4-S1 (1) }\end{array}$ & 16 \\
\hline TLIF w/ cage & 26 & $\begin{array}{l}\text { L4-5 (16) } \\
\text { L5-S1 (8) } \\
\text { L4-S1 (2) }\end{array}$ & 28 \\
\hline Posterolateral fusion & 23 & $\begin{array}{l}\text { L3-5 (3) } \\
\text { L4-5 (16) } \\
\text { L5-S1 (2) } \\
\text { L4-S1 (2) }\end{array}$ & 28 \\
\hline $\begin{array}{l}\text { Lumbar decompres- } \\
\text { sion }\end{array}$ & 37 & $\begin{array}{r}\text { L4-5 (15) } \\
\text { L5-S1 (12) } \\
\text { L4-S1 (10) }\end{array}$ & 47 \\
\hline Discectomy & 30 & $\begin{array}{l}\text { L3-4 (2) } \\
\text { L4-5 (12) } \\
\text { L5-S1 (15) } \\
\text { L4-S1 (1) }\end{array}$ & 31 \\
\hline $\begin{array}{l}\text { Thoracic decompres- } \\
\text { sion \& posterolateral } \\
\text { fusion }\end{array}$ & 2 & $\begin{array}{l}\mathrm{T} 10-12(1) \\
\mathrm{T} 11-\mathrm{L} 1(1)\end{array}$ & 4 \\
\hline
\end{tabular}

Pts = patients; TLIF = transforaminal lumbar interbody fusion.

shown in Table 1. A breakdown of the 149 scheduled surgeries is summarized in Table 2. All patients were tested for COVID-19 with the polymerase chain reaction (PCR) test prior to surgery.

Visual analog scale (VAS) and Oswestry Disability Index (ODI) scores were assessed preoperatively, immediately after surgery, and 1 year after surgery. Patient satisfaction was assessed with a simple questionnaire containing the following questions. 1) Would you recommend this type of anesthesia to other patients? 2) If you had the same condition again, would you accept the same type of anesthesia?

\section{Anesthetic Technique}

Standard monitors were applied to the patient in the operating room, and the patient was placed in a lateral position. After sterile preparation and draping of the back, $5 \mathrm{~mL}$ to $10 \mathrm{~mL}$ of $2 \%$ lidocaine was used to infiltrate the third or fourth lumbar intervertebral space. A 25-gauge Sprotte spinal needle was then introduced into the intervertebral space until free flow of cerebrospinal fluid was visualized after removal of the spinal needle stylet. At this time, $3 \mathrm{~mL}$ to $5 \mathrm{~mL}$ of $0.5 \%$ bupivacaine and $0.3 \mathrm{mg}$ of morphine were injected into the spinal canal. The patient was turned supine and remained in this position for 10 


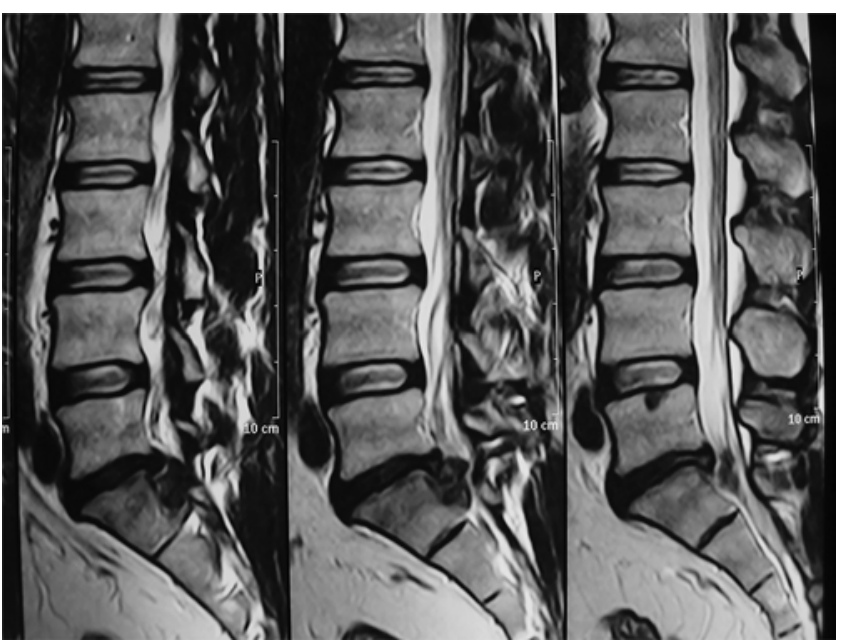

FIG. 1. Sagittal MR images demonstrating a caudally migrated disc at L5-S1 in a 50-year-old male patient who presented with significant left radicular pain that failed to respond to conservative management.

minutes, after which the patient was transferred to the prone position on the surgical frame. All patients received an antiemetic regimen of pantoprazole and ondansetron. For all fusion and revision cases, a silicone urinary catheter was inserted under aseptic conditions.

\section{Case Presentation}

A 50-year-old male patient presented with significant left radicular pain that failed to respond to conservative management. Sagittal MR images demonstrated a caudally migrated disc at L5-S1 (Fig. 1), and axial MR images revealed compression of the spinal nerve and dural sac (Fig. 2). After preoperative investigations were completed, including COVID-19 PCR testing, the patient was brought in for surgery. The patient was placed in the lateral decubitus position for spinal anesthesia (Fig. 3) and was able to assist with their own positioning (Fig. 4). The disc fragment compressing the spinal nerve was successfully removed (Fig. 5).

\section{Results}

Overall, 149 patients received successful spine surgery under spinal anesthesia. The mean age of our cohort was 47.5 years (22-85 years), and included 49 males and 100 females. The mean estimated blood loss (EBL) across all procedures was $385 \pm 156 \mathrm{~mL}$, and the operative time ranged from 45 to 300 minutes. Under spinal anesthesia, the patients were able to assist with their positioning in the beginning of surgery and were capable of conversation and interaction during surgery. A visually administered, intrathecal injection of an extra dose of spinal anesthesia was necessary for 7 patients. This was possible because the dura mater was exposed for decompression procedures. In

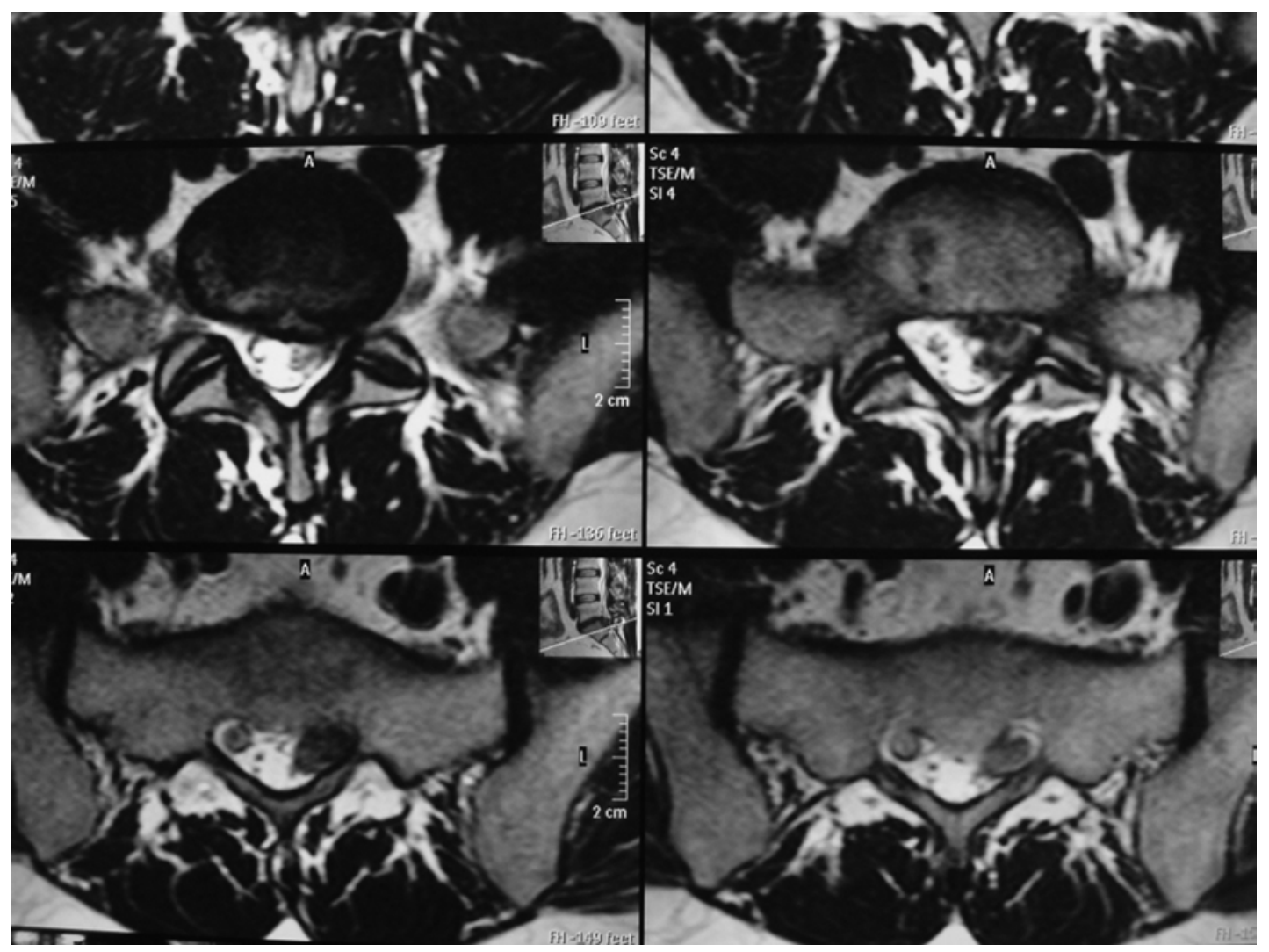

FIG. 2. Axial MR images obtained in the same patient, demonstrating compression of the spinal nerve and dural sac. 


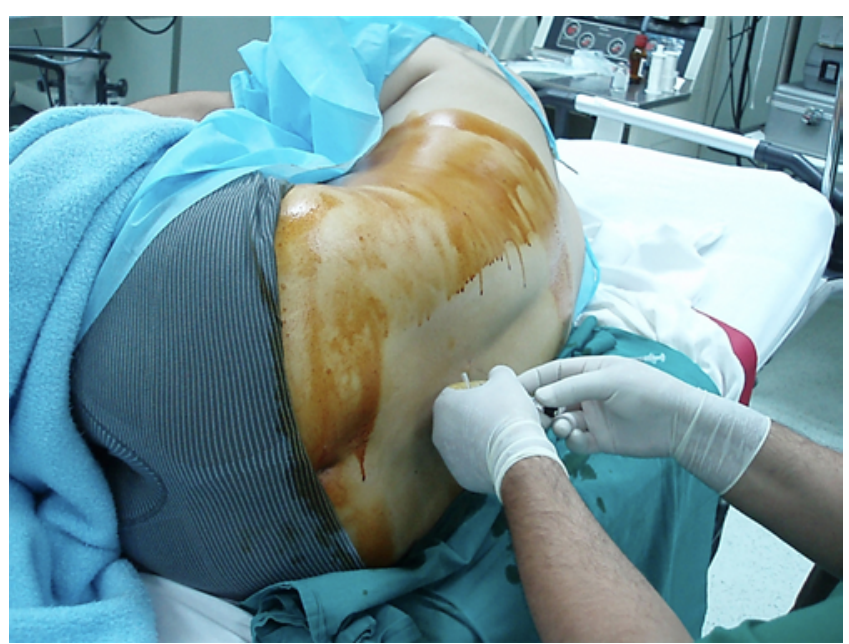

FIG. 3. Intraoperative photograph showing the patient placed in the lateral decubitus position for administration of spinal anesthesia.

the case of a 5-hour, three-level revision, the patient was converted to GA after 3 hours with spinal anesthesia.

There were no major cardiopulmonary complications, and there were no intraoperative complications that affected patient satisfaction. Patients were able to eat immediately after surgery. The mean time to ambulation, with or without use of a walking aid, was $19 \pm 7$ hours. Patients who underwent fusion were allowed to rest on the 1 st postoperative day, with ambulation encouraged on the 2nd postoperative day. Decompression patients were dis- charged on the 2 nd postoperative day, and fusion and revision patients were discharged on the 3rd postoperative day.

Patients demonstrated excellent postoperative pain relief, as measured by VAS and ODI scores, which was maintained and improved at the 1-year postoperative follow-up (Table 3). There were no 30- or 90-day readmissions. There were no cases of patients contracting COVID-19 in the perioperative setting.

Of 149 patients, 124 were satisfied with spinal anesthesia and would recommend spinal anesthesia to another patient. The remaining 25 patients, while not satisfied with spinal anesthesia, were still pleased with their postoperative clinical and functional outcomes.

\section{Discussion}

When administering anesthesia for spine surgery, robust measures must be taken to ensure patient safety and satisfaction, as well as to reduce postoperative pain and complications. ${ }^{8}$ This study demonstrated that patients who underwent spine surgery with spinal anesthesia had better clinical outcomes than those who received GA. These results are consistent with those reported in the literature. ${ }^{2,6}$

Currently, GA is the most common type of anesthesia used. This might be because spine surgery was previously associated with considerable morbidity, including blood loss, retraction of musculature, and lengthy operative time, necessitating good airway control. Additionally, there was great variance in these features, so prediction of surgery duration and invasiveness was challenging. With newer modern techniques, including minimally invasive surgery and increasing familiarity with spine pathology, spine sur-

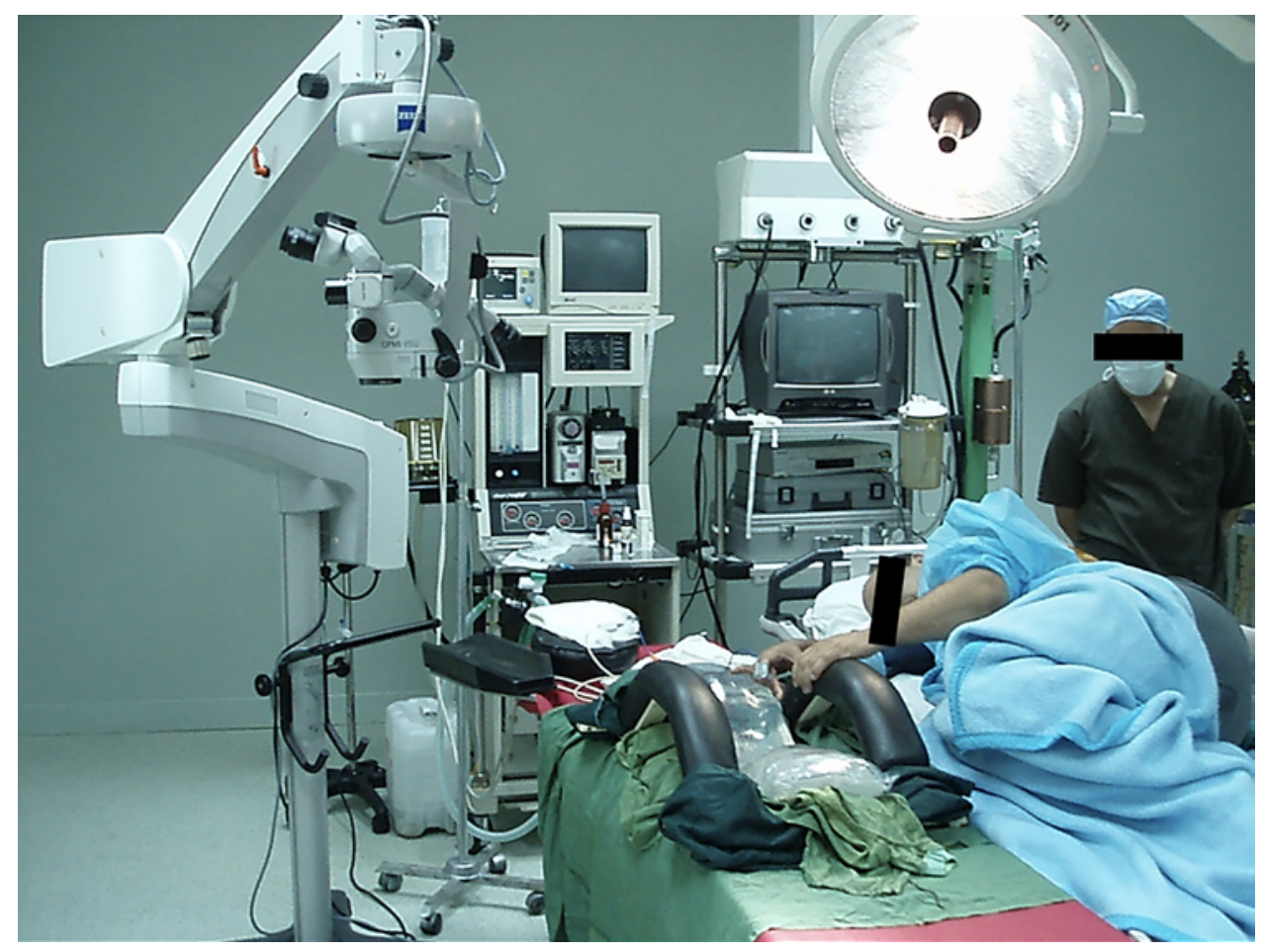

FIG. 4. Intraoperative photograph showing the awake patient assisting in his own positioning. 


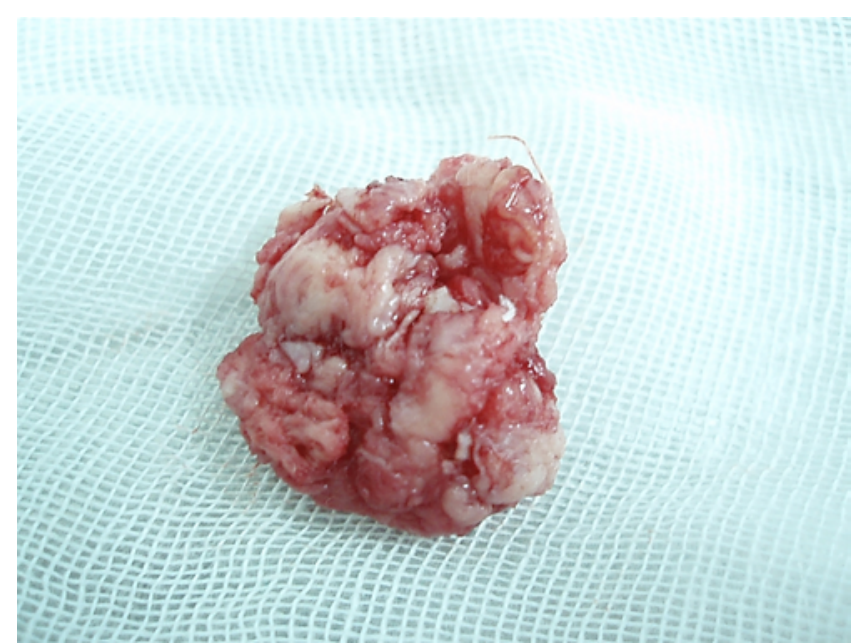

FIG. 5. Photograph showing the successfully removed disc fragment that was compressing the spinal nerve.

gery has become more controlled, facilitating the use of spinal anesthesia.

Spinal anesthesia not only minimizes the cardiopulmonary concerns relevant to GA but also is associated with less postoperative nausea and vomiting, less postoperative narcotic use, and less economic burden..$^{7-16}$ Challenges associated with spinal anesthesia, however, include increased stress on the anesthesiologist and challenges when interpreting postoperative neurological examination results. ${ }^{10}$

The advantages of spinal anesthesia when compared with GA have been researched and reported. Although some studies have found that spinal anesthesia is merely comparable to $\mathrm{GA},{ }^{17}$ a large number of studies have found spinal anesthesia is, in fact, superior at providing postoperative pain relief, maintaining hemodynamic stability, and reducing postoperative adverse effects. Randomized controlled trials have demonstrated that spinal anesthesia is associated with reduced postoperative nausea and vomiting, a shorter hospital length of stay, less intraoperative blood loss, reduced changes in heart rate and blood pressure, reduced risk of deep vein thrombosis, superior glycemic control in patients with diabetes, reduced ocular complications, and reduced cost. . $^{2,12,13,18-20}$

There were no anesthetic failures or episodes of airway compromise, desaturation, or cardiovascular instability. The use of spinal anesthesia circumvented the deleterious physiological consequences of prone positioning under GA entirely. It is thought that the maintenance of spontaneous ventilation results in lower intrathoracic pressure and less subsequent distension of the epidural veins, leading to a lower EBL across all procedures. ${ }^{18}$ There were no incidences of postdural puncture headache.

\section{Spine Surgery and the COVID-19 Pandemic}

Spine surgery, and particularly triaging spine surgery, became and remains difficult due to the COVID-19 pandemic. As a result of the pandemic, there have been significant shortages of medications, supplies, and providers.
TABLE 3. Clinical and functional results

\begin{tabular}{ccc}
\hline \multicolumn{1}{c}{ Operative Data } & Value & p Value \\
\hline Mean EBL \pm SD, $\mathrm{mL}$ & $385 \pm 156$ & \\
\hline Mean op time \pm SD, mins & $128 \pm 34$ & \\
\hline Functional outcome, mean \pm SD & & \\
\hline Preop VAS score & $7.30 \pm 0.89$ & \\
\hline Immediately postop VAS score & $2.08 \pm 1.01$ & $<0.001$ \\
\hline 1-yr postop VAS score & $1.90 \pm 0.92$ & $<0.002$ \\
\hline Preop ODI score & $44.01 \pm 6.78$ & \\
\hline Immediately postop ODI score & $15.30 \pm 4.62$ & $<0.002$ \\
\hline 1-yr postop ODI score & $13.5 \pm 4.73$ & $<0.002$ \\
\hline Time to ambulation, hrs & $19 \pm 7$ & \\
\hline Other clinical outcomes & & \\
\hline Satisfaction w/ anesthesia & $83.2 \%$ & \\
\hline 30-day readmissions & None & \\
\hline 90-day readmissions & None & \\
\hline Length of stay, nights & & \\
\hline Decompression & 1 & \\
\hline Fusion & 2 & \\
\hline Revision & 2 & \\
\hline
\end{tabular}

Available resources have been understandably shunted to the front lines of the fight against COVID-19. While urgent spinal surgeries do exist, many spinal surgeries are theoretically "elective." Therefore, resource management in times of scarcity greatly reduces a medical center's spine surgery throughput capacity. A prime example of this is Tan Tock Seng Hospital, located in the epicenter of Singapore's COVID-19 outbreak, which reported a 50\% reduction in elective procedures in the first 6 weeks of the outbreak..$^{15}$ Many other health systems have placed a block on elective procedures during particularly difficult periods of this pandemic. For these reasons, there have been efforts to establish guidelines for appropriate courses of action given specific surgical spine pathologies..$^{21,22}$ Verification of such guidelines and retrospective analysis will be critical to establish evidence-based systems for spinal care in the event of a future viral outbreak.

There is evidence that awake spine surgery is associated with reduced cost,${ }^{23}$ length of stay, and healthcare resource utilization. Therefore, it is likely that in any potential future setting of medical scarcity, awake spine surgery could increase a medical center's capacity to perform spinal procedures as it would be associated with less shunting of resources away from the front lines. This phenomenon has been documented in the setting of awake orthopedic surgery programs. ${ }^{24}$ In this sense, awake spinal anesthesia has the potential to play a major role in spinal care in the event of a future pandemic.

\section{Conclusions}

Our study supports the growing precedent that awake lumbar spinal anesthesia is a safe and effective alternative to GA and is associated with fewer intraoperative and postoperative complications, as well as increased patient 
and surgeon satisfaction. Furthermore, awake spinal anesthesia may play a critical role in maintaining spinal surgical care in potential future pandemics.

\section{References}

1. Street JT, Lenehan BJ, DiPaola CP, Boyd MD, Kwon BK, Paquette SJ, et al. Morbidity and mortality of major adult spinal surgery. A prospective cohort analysis of 942 consecutive patients. Spine J. 2012;12(1):22-34.

2. Zorrilla-Vaca A, Healy RJ, Mirski MA. A comparison of regional versus general anesthesia for lumbar spine surgery: a meta-analysis of randomized studies. J Neurosurg Anesthesiol. 2017;29(4):415-425.

3. Smith G, D'Cruz JR, Rondeau B, Goldman J. General anesthesia for surgeons. In: StatPearls. StatPearls Publishing; 2021. Accessed October 11, 2021. https://www.ncbi.nlm.nih. gov/books/NBK493199/

4. Sagát P, Bartík P, Prieto González P, Tohănean DI, Knjaz D. Impact of COVID-19 quarantine on low back pain intensity, prevalence, and associated risk factors among adult citizens residing in Riyadh (Saudi Arabia): a cross-sectional study. Int J Environ Res Public Health. 2020;17(19):7302.

5. Moretti A, Menna F, Aulicino M, Paoletta M, Liguori S, Iolascon G. Characterization of home working population during COVID-19 emergency: a cross-sectional analysis. Int J Environ Res Public Health. 2020;17(17):6284.

6. Kolcun JPG, Brusko GD, Basil GW, Epstein R, Wang MY. Endoscopic transforaminal lumbar interbody fusion without general anesthesia: operative and clinical outcomes in 100 consecutive patients with a minimum 1-year follow-up. Neurosurg Focus. 2019;46(4):E14.

7. Lessing NL, Edwards CC II, Brown CH IV, Ledford EC, Dean CL, Lin C, Edwards CC. Spinal anesthesia in elderly patients undergoing lumbar spine surgery. Orthopedics. 2017; 40(2):e317-e322.

8. Jellish WS, Thalji Z, Stevenson K, Shea J. A prospective randomized study comparing short- and intermediate-term perioperative outcome variables after spinal or general anesthesia for lumbar disk and laminectomy surgery. Anesth Analg. 1996;83(3):559-564.

9. McLain RF, Tetzlaff JE, Bell GR, Uwe-Lewandrowski K, Yoon HJ, Rana M. Microdiscectomy: spinal anesthesia offers optimal results in general patient population. J Surg Orthop Adv. 2007;16(1):5-11.

10. Chen HT, Tsai CH, Chao SC, Kao TH, Chen YJ, Hsu HC, et al. Endoscopic discectomy of L5-S1 disc herniation via an interlaminar approach: prospective controlled study under local and general anesthesia. Surg Neurol Int. 2011;2:93.

11. De Rojas JO, Syre P, Welch WC. Regional anesthesia versus general anesthesia for surgery on the lumbar spine: a review of the modern literature. Clin Neurol Neurosurg. 2014;119: $39-43$.

12. Tetzlaff JE, Dilger JA, Kodsy M, al-Bataineh J, Yoon HJ, Bell GR. Spinal anesthesia for elective lumbar spine surgery. J Clin Anesth. 1998;10(8):666-669.

13. Agarwal P, Pierce J, Welch WC. Cost analysis of spinal versus general anesthesia for lumbar diskectomy and laminectomy spine surgery. World Neurosurg. 2016;89:266-271.

14. Kahveci K, Doger C, Ornek D, Gokcinar D, Aydemir S, Ozay R. Perioperative outcome and cost-effectiveness of spinal versus general anesthesia for lumbar spine surgery. Neurol Neurochir Pol. 2014;48(3):167-173.
15. Soh TLT, Ho SWL, Yap WMQ, Oh JY. Spine surgery and COVID-19: challenges and strategies from the front lines. $J$ Bone Joint Surg Am. 2020;102(12):e56.

16. Ulutas M, Secer M, Taskapilioglu O, Karadas S, Akyilmaz AA, Baydilek Y, et al. General versus epidural anesthesia for lumbar microdiscectomy. J Clin Neurosci. 2015;22(8):13091313.

17. Sekerak R, Mostafa E, Morris MT, Nessim A, Vira A, Sharan A. Comparative outcome analysis of spinal anesthesia versus general anesthesia in lumbar fusion surgery. J Clin Orthop Trauma. 2020;13:122-126.

18. Attari MA, Mirhosseini SA, Honarmand A, Safavi MR. Spinal anesthesia versus general anesthesia for elective lumbar spine surgery: A randomized clinical trial. J Res Med Sci. 2011;16(4):524-529.

19. Gottschalk A, Rink B, Smektala R, Piontek A, Ellger B, Gottschalk A. Spinal anesthesia protects against perioperative hyperglycemia in patients undergoing hip arthroplasty. $J$ Clin Anesth. 2014;26(6):455-460.

20. Shen Y, Drum M, Roth S. The prevalence of perioperative visual loss in the United States: a 10-year study from 1996 to 2005 of spinal, orthopedic, cardiac, and general surgery. Anesth Analg. 2009;109(5):1534-1545.

21. Donnally CJ III, Shenoy K, Vaccaro AR, Schroeder GD, Kepler CK. Triaging spine surgery in the COVID-19 Era. Clin Spine Surg. 2020;33(4):129-130.

22. Soffin EM, Reisener MJ, Sama AA, Beckman JD, Liguori GA, Lebl DR, et al. Essential spine surgery during the COVID-19 pandemic: a comprehensive framework for clinical practice from a specialty orthopedic hospital in New York City. HSS J. 2020;16(1)(suppl):29-35.

23. Scott J, Huskisson EC. Graphic representation of pain. Pain. 1976;2(2):175-184.

24. Turcotte JJ, Gelfand JM, Jones CM, Jackson RS. Development of a low-resource operating room and a wide-awake orthopedic surgery program during the COVID-19 pandemic. Surg Innov. 2021;28(2):183-188.

\section{Disclosures}

Dr. Abd-El-Barr: Consultant for Spineology and DePuy Synthes. Dr. Elhawary: consultant for Spinecraft.

\section{Author Contributions}

Conception and design: Abd-El-Barr, Khattab, Montaser, El Ghamry, Elhawary. Acquisition of data: Khattab, El Ghamry, Elhawary. Analysis and interpretation of data: Abd-El-Barr, Khattab, Sykes, Montaser, El Ghamry, Elhawary. Drafting the article: all authors. Critically revising the article: Abd-El-Barr, Khattab, Sykes, Waguia, Montaser, El Ghamry. Reviewed submitted version of manuscript: Khattab, Waguia, El Ghamry, Elhawary. Approved the final version of the manuscript on behalf of all authors: Abd-El-Barr. Statistical analysis: Khattab. Administrative/technical/material support: Khattab, Elhawary. Study supervision: Khattab, Elhawary.

\section{Correspondence}

Muhammad M. Abd-El-Barr: Duke University Medical Center, Durham, NC.m.abdelbarr@duke.edu. 